\title{
Assessing guideline impact on referral patterns of post- prostatectomy patients to radiation oncologists
}

\author{
Amandeep Taggar, MD; Majed Alghamdi, MD; ${ }^{1}$ Derek Tilly, MD; ${ }^{2}$ Xanthoula Kostaras, MD; Marc Kerba, MD; \\ Siraj Husain, MD; Geoff Gotto, MD; Michael Sia, MD'
}

'Department of Oncology, Division of Radiation Oncology, University of Calgary, Tom Baker Cancer Centre, Calgary, AB, Canada; ${ }^{2}$ Guideline Resource Unit, Cancer Control Alberta, Calgary, AB, Canada; ${ }^{3}$ Department of Surgery, Division of Urology, University of Calgary, AB, Canada

Cite as: Can Urol Assoc J 2016;10(9-10):314-8. http://dx.doi.org/10.5489/cuaj.3539

See related commentary on page 319.

\section{Abstract}

Introduction: Adjuvant radiotherapy (aRT) can improve biochemical progression-free survival in patients with high-risk features (HRF) after radical prostatectomy (RP). Guidelines from Alberta and the Genitourinary Radiation Oncologists of Canada (GUROC) recommend that patients with HRF be referred to radiation oncologists (RO) based on the findings from three randomized, controlled trials (RCT). Our study examines the impact of these recommendations both pre- (2005) and post- (2012) publication of RCT and GUROC guideline establishment.

Methods: Patients undergoing RP during 2005 and 2012 were identified from the provincial cancer registry. Charts were retrospectively reviewed and variables of interest were linked to the registry data. RO referral patterns for each year were determined and variables influencing referral (extracapsular extension, positive margin, seminal vesicle invasion, and post-RP prostate-specific antigen [PSA]) were compared.

Results: Median time to referral was 26.4 months in 2005 compared to 3.7 months $2012(\mathrm{p}<0.001)$. Among patients referred post-RP, a higher proportion was referred within six months in $2012(21 \%)$ as compared to $2005(13 \%)(p=0.003)$. Among eligible patients in $2012,30 \%$ were referred for discussion of aRT compared to $24 \%$ in $2005(p=0.003)$. There was a marked drop in patients referred for salvage radiation therapy beyond six months and a rise in the number of patients who are never referred.

Conclusions: Despite an increase in referral rates to RO post-RP from 2005-2012, more than 50\% of those patients with HRF did not receive a referral. Initiatives aimed at improving multidisciplinary care and guideline adherence should be undertaken.

\section{Introduction}

In 2015, 24000 new cases of prostate cancer diagnosis are anticipated in Canada (Canadian Cancer Stats 2015). Of these patients, approximately $50 \%$ will undergo radi- cal prostatectomy (RP). ${ }^{1}$ Despite improvements in surgical techniques, some patients will have high-risk features (HRF) (i.e., positive margins $[\mathrm{M}+]$, extracapsular extension [ECE], and seminal vesicle invasion [SVI]) post-resection without biochemical evidence of disease. Phase 3 randomized, controlled trials (RCT) have shown that adjuvant radiation therapy (aRT) for patients with HRF improves biochemical relapse-free survival and recurrence-free survival. ${ }^{2-4}$ The update of the Southwest Oncology Group (SWOG) 8794 trial with median followup of 12.9 years has also shown an improvement in metastasis-free survival and overall survival. ${ }^{5}$ Similarly, the 10-year followup data from the European Organization for Research and Treatment of Cancer (EORTC) 22911 trial confirms biochemical progression-free survival benefit and reports a clinical progression-free survival benefit with patients who underwent aRT. ${ }^{6}$

Following publication of these trials and a meta-analysis, ${ }^{7}$ the Genitourinary Radiation Oncologists of Canada (GUROC) issued a consensus statement advising a consultation with a radiation oncologist (RO) early in the postoperative period to discuss benefits and side effects of aRT in those with HRF. ${ }^{8}$ The American Urological Association (AUA) and American Society for Therapeutic Radiation Oncology (ASTRO) have also issued similar recommendations in their guidelines. ${ }^{9}$ Furthermore, the American Society of Clinical Oncology has also endorsed these recommendations. ${ }^{10}$

The Alberta Health Services Cancer Control clinical practice guidelines, initially published in 2005 and updated yearly thereafter, reflect the phase 3 RCT evidence and recommendation of GUROC.

The goal of this study is to assess referral pattern to $\mathrm{RO}$ post-RP in order to determine the impact of published recommendations and compliance with our provincial guidelines.

\section{Methods}

All men who were $\geq 18$ years of age and received a diagnosis of prostate adenocarcinoma in Alberta in $2005(n=1794)$ and 
$2012(n=2149)$ were identified through the Alberta Cancer Registry, gold-certified by the North American Association of Central Cancer Registries, using discharge abstract database (DAD) with an error rate of $<5 \% .{ }^{11}$ Only patients who underwent RP were included in the study cohort $(n=658$ in 2005; $\mathrm{n}=485$ in 2012). Patients were excluded if they were treated out of province or if they had incomplete/inaccessible medical records (final cohort: $n=374$ in 2005; $n=476$ in 2012). Patient characteristics, disease characteristics, pathological characteristics, and referrals to RO were confirmed through manual chart review. Patients were considered to have HRF post-RP if they had ECE, M+, or SVI. Patients were considered to have had a $R O$ referral if there was any evidence in their medical record of an appointment with a RO.

All data was collected in accordance with the Health Information Act of Alberta after ethical review using the ARECCI method. ${ }^{12}$

Statistical analyses were performed using SPSS V.22 (IBM, Armonk, NY, U.S.) or SigmaPlot (San Jose, CA, U.S.). T-test or Mann-Whitney $U$ test were used for monovariable comparisons of quantitative data points. Chi-square or Fisher's exact test were used for monovariable comparisons of qualitative data points. A linear regression logistic multivariable model was constructed to assess association of variables with referral within six months post-RP.

All financial and material support to conduct this study and prepare this manuscript were provided through operational funding by CancerControl Alberta, Alberta Health Services.

\section{Results}

In 2005 and 2012, 1794 and 2149 men were diagnosed with prostate cancer, respectively. A total of $658(36.7 \%)$ patients underwent RP in 2005 compared to 485 (22.6\%) in $2012(p<0.001)$. It is worth noting that the decrease in prostatectomy use in 2012 is likely the result of increased use of active surveillance in patients with low-risk disease. In addition, prostate brachytherapy developed as an alternative to prostatectomy in Alberta; the number of prostate brachytherapy in Alberta increased from 138 implants in 2005 to 307 implants in 2012.

Clinical records of 374 patients who underwent RP in 2005 and 476 in 2012 were available for analysis. Table 1 summarizes the patient, disease, and pathological characteristics. In both years, age and prostate-specific antigen (PSA) at diagnosis were similar ( $p>0.05)$. However, a significantly higher proportion of men with Gleason score (GS) $\geq 8$ underwent RP in 2012 compared to $2005(p<0.001)$. There was significantly higher proportion of patients with positive surgical margins and detectable PSA post-RP in 2005 compared to $2012(\mathrm{p}<0.001)$.

In 2005, $163(43.6 \%)$ patients were referred to a RO as compared to $133(27.9 \%)$ in 2012 . Overall median time to

\begin{tabular}{|c|c|c|c|}
\hline & $2005(n=374)$ & $2012(n=476)$ & p value \\
\hline Age, median (range) & $61.6(37.8-79.0)$ & $61.6(35.9-84.2)$ & 0.347 \\
\hline $\begin{array}{l}\text { Gleason at diagnosis, } \\
\mathrm{n}(\%)\end{array}$ & & & $<0.001$ \\
\hline$\leq 6$ & $224(60.3)$ & $137(29.3)$ & \\
\hline 7 & $139(37.5)$ & $270(57.7)$ & \\
\hline$\geq 8$ & $8(2.2)$ & $61(13.0)$ & \\
\hline Unknown & 3 & 8 & \\
\hline $\begin{array}{l}\text { PSA at diagnosis, } \\
\text { n (\%) }\end{array}$ & & & 0.205 \\
\hline$<10$ & $267(79.7)$ & 399 (84.5) & \\
\hline $10-20$ & $53(15.8)$ & $57(12.1)$ & \\
\hline$>20$ & $15(4.5)$ & $16(3.4)$ & \\
\hline Unknown & 39 & 4 & \\
\hline $\begin{array}{l}\text { Extracapsular } \\
\text { extension, } \mathrm{n}(\%)\end{array}$ & & & 0.491 \\
\hline Present & $86(24.8)$ & $126(26.9)$ & \\
\hline Absent & $261(75.2)$ & $342(73.1)$ & \\
\hline Unknown & 27 & 8 & \\
\hline $\begin{array}{l}\text { Surgical margins, } \\
\mathrm{n}(\%)\end{array}$ & & & $<0.001$ \\
\hline Positive & $140(40.2)$ & $129(27.4)$ & \\
\hline Negative & $208(59.8)$ & $342(72.6)$ & \\
\hline Unknown & 26 & 5 & \\
\hline $\begin{array}{l}\text { Seminal vesicle } \\
\text { invasion, } \mathrm{n}(\%)\end{array}$ & & & 0.080 \\
\hline Present & $41(11.8)$ & $38(8.1)$ & \\
\hline Absent & $307(88.2)$ & $430(91.9)$ & \\
\hline Unknown & 26 & 8 & \\
\hline $\begin{array}{l}\text { PSA post-surgery, } \\
\text { n (\%) }\end{array}$ & & & $<0.001$ \\
\hline Detectable & $96(29.4)$ & $48(11.7)$ & \\
\hline Undetectable & $231(70.6)$ & $363(88.3)$ & \\
\hline Unknown & 47 & 65 & \\
\hline $\begin{array}{l}\text { Lymph node status, } \\
\text { n (\%) }\end{array}$ & & & 0.168 \\
\hline Positive & $14(4.4)$ & $12(2.6)$ & \\
\hline Negative & 307 (95.6) & $454(97.4)$ & \\
\hline Unknown & 53 & 10 & \\
\hline
\end{tabular}

PSA: prostate-specific antigen.

referral was longer in 2005 compared to 2012 (26.4 vs. 3.7 months; $\mathrm{p}<0.001)$. Patients with ECE, $\mathrm{M}+$, and SVI also had longer median referral time in 2005 compared to 2012: 24.4 (0.5-99.0) vs. 3.3 (0.3-22.7) months; 20.7 (0.5-99.0) vs. 2.9 (0.5-22.0) months; and 14.9 (0.5-99.0) vs. $3.3(0.8-22.7)$ months, respectively. Fig. 1 displays the referral distributions.

Fig. 2 and Table 2 describe timing of referral (within six months of RP, after six months of RP, or never referred) to a RO if patients had HRF. There were more patients referred within six months of RP in 2012 as compared to 2005, but significantly less were referred after six months and a large proportion were never referred in 2012 ( $p<0.001)$. Subgroup analysis of patients 


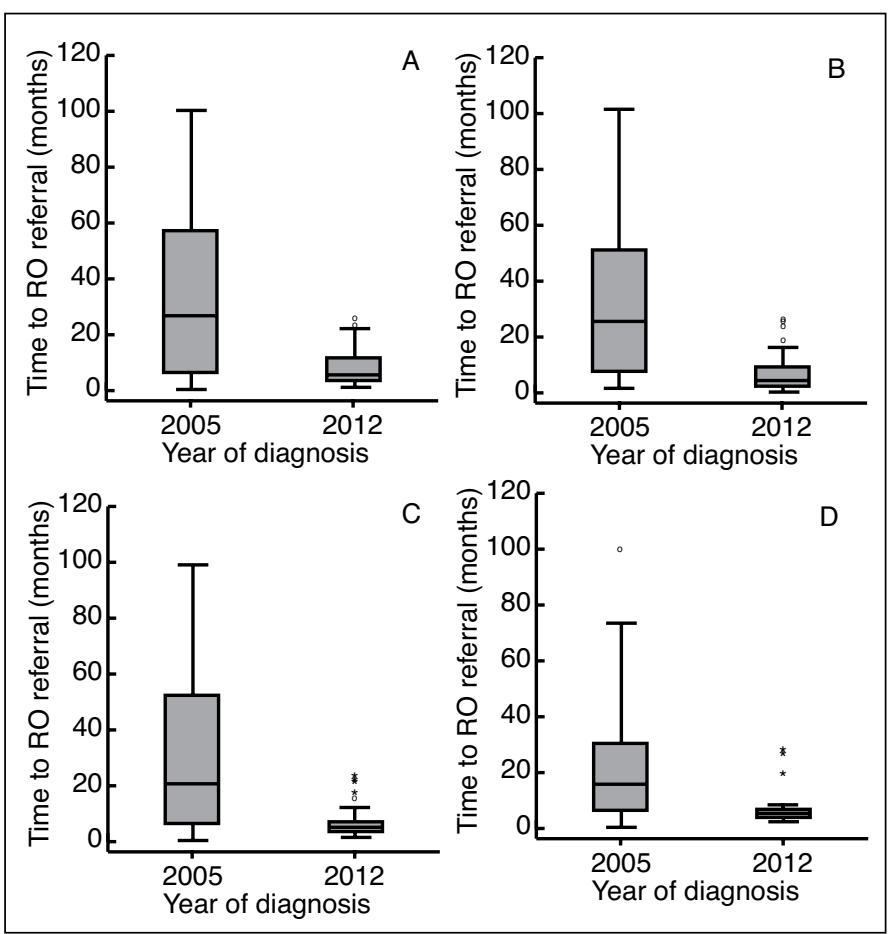

Fig. 1. Radiation oncologist referral from time of radical prostatectomy, median (range); (A) all patients, $26.4(0.5-102.0)$ vs. $3.7(0.3-26.1) ;(B)$ patients with extracapsular extension, 24.4 (0.5-99.0) vs. $3.3(0.3-22.7)$; (C) patients with positive margins, $20.7(0.5-99.0)$ vs. $2.9(0.5-22.0)$; and (D) patients with seminal vesicle invasion, $14.9(0.5-99.0)$ vs. $3.3(0.8-22.7)$ months. Top line is maximum, bottom line is minimum, median is bolded with third and first quartile above and below (circles=outliers). $\mathrm{RO}$ : radiation oncologist.

with HRF and those referred within six months showed that a higher proportion of these patients were referred in 2012 as compared to 2005, unless patients had all three HRF.

Fig. 3 displays patients who had HRF, undetectable PSA $(<0.2 \mathrm{ng} / \mathrm{ml})$, and were referred within six months post-RP (i.e., aRT). In 2012, only $30 \%$ of the patients were referred to $\mathrm{RO}$ for discussion regarding aRT. This is slightly higher than the $24 \%$ referred in 2005 ( $p=0.003$ ). However, a significant proportion of patients were not referred in either of the two years examined (Fig. 3).

On univariable analysis, year of diagnosis (2012), as well as presence of ECE, $\mathrm{M}+$, and SVI were found to be associated with referral to RO within six months $(p<0.001)$. On

Table 2. Referral of patients to RO within six months of RP if HRF were present (post-RP PSA excluded)

\begin{tabular}{lccc}
\hline & $\mathbf{2 0 0 5}$ & $\mathbf{2 0 1 2}$ & p value \\
\hline Extracapsular extension, n (\%) & $10(23.8)$ & $32(72.5)$ & $<0.001$ \\
Positive margins, n (\%) & $21(34.4)$ & $23(79.3)$ & $<0.001$ \\
Seminal vesicle invasion, n (\%) & $10(38.5)$ & $12(80.0)$ & 0.010 \\
$>1$ pathological features, n (\%) & & & \\
$\quad$ Two & $5(21.7)$ & $16(76.2)$ & $<0.001$ \\
$\quad$ Three & $7(50.0)$ & $7(87.5)$ & 0.079 \\
\hline
\end{tabular}

HRF: high-risk factors; PSA: prostate-specific antigen; RO: radiation oncologist; RP: radical prostatectomy.

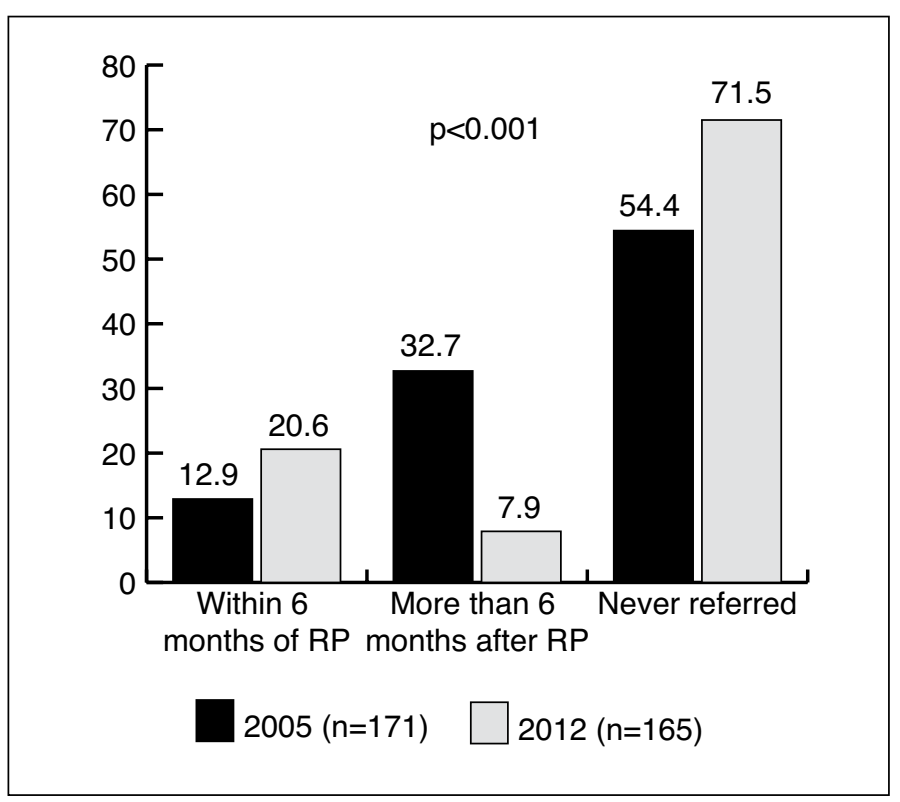

Fig. 2. Timing of referral to radiation oncologist for patients with at least one high-risk feature. RP: radical prostatectomy.

multivariable analysis, only the year of diagnosis $(p<0.001)$ and $M+(p<0.001)$ remained statistically significant.

\section{Discussion}

In patients with HRF post-RP, risk of local recurrence is more than $60 \% .^{5,6}$ Many international urologic and oncologic organizations have endorsed offering aRT to these patients, as it improves biochemical progression-free survival by $20-30 \%{ }^{2-4}$ and metastasis-free survival by $10 \%,{ }^{5}$ as well as clinical progression-free survival. ${ }^{5,6}$ The impact on overall survival (OS) is uncertain, as the SWOG trial shows an improvement in OS, ${ }^{5}$ while the EORTC trial does not. ${ }^{6}$ A Cochrane review concluded that aRT improves OS and metastasis-free survival at 10 years. ${ }^{13}$

CancerControl Alberta has a process to develop treatment guidelines based on best available evidence. In 2005, guidelines recommended aRT for patients with $\mathrm{M}+$, PSA $<2$ ng/ml, PSA doubling time $>10$ months, and GS $\leq 7$. In 2012, these guidelines reflected RCT evidence and international consensus guidelines. The evidence and changes to guidelines are discussed at the annual provincial genitourinary meetings attended by urologists, radiation oncologists, and medical oncologists. The observed modest increase in the referral rates of patients with HRF seen in 2012 indicates ongoing dialogue among various healthcare members treating prostate cancer. Importantly, the observed increase in referral within six months of RP is potentially a result of guideline recommendations. However, a decline in referral rate greater than six months post-RP was noted (Fig. 2). This observation may be attributable to: (1) a higher number of 


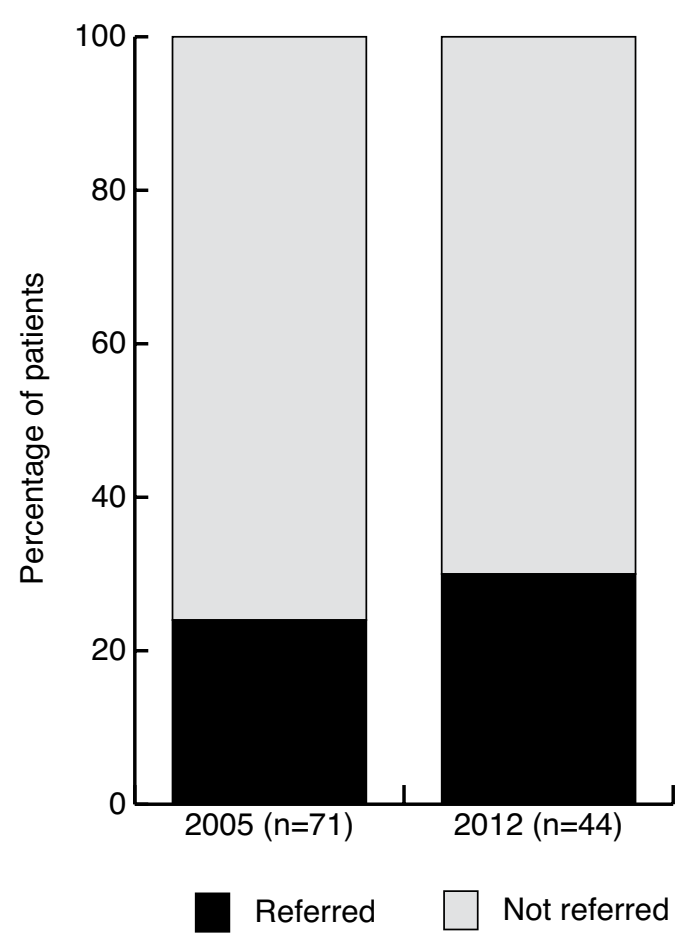

Fig. 3. Proportion of patients referred to a radiation oncologist for adjuvant radiotherapy consultation post-radical prostatectomy.*

*Presence of at least one high-risk feature, prostate-specific antigen $<0.2 \mathrm{ng} / \mathrm{ml}$, and referral within six months of radical prostatectomy.

patients being referred for salvage RT in 2005; and (2) inclusion of some patients referred for palliative RT many years post-RP in this cohort. This latter observation is supported by median time to referral, which was significantly longer for the 2005 cohort compared to the 2012 one.

\section{Potential factors contributing to slow uptake of guideline recommendations}

There are published models that estimate optimal radiotherapy referral and use. ${ }^{14-16}$ These models would suggest $100 \%$ of patients with undetectable PSA and at least one HRF should be referred to RO for discussion of aRT. Unfortunately, the observed rate was $30 \%$ in 2012 , only slightly higher than in 2005 (24\%). Overall, the low referral rate in 2005 can be explained by lack of level I or other sufficiently good quality of evidence to support radiotherapy in this setting. With the arrival of new study results, the reason for suboptimal referral rates in 2012 is unclear. Potential explanations include: (1) patient and physician concern regarding radiotherapy toxicity; (2) lack of agreement among referring physicians that guideline recommendations are appropriate (gatekeeper effect); (3) lack of clear evidence regarding the optimal timing of radiotherapy post-RP; and (4) lack of perceived OS benefit.

Several publications have reported utilization rates of RT ranging from $1.8-11 \%$ post-RP for patients with HRF. ${ }^{17-22}$
Sineshaw et $\mathrm{al}^{23}$ looked at the National Cancer Data Base in the U.S. and found a significant drop in the utilization rate of postoperative RT in prostate cancer patients with adverse pathological factors between 2005 and 2011 from $9.1-7.3 \%$. However, this study and the other cited publications do not report the referral rates to a radiation oncology department. To our knowledge, this is the first published report detailing referral rates at the population level. We believe it is important to identify the actual referral rate, rather than just RT utilization rate to assess the guideline implementation and adherence.

In our analysis the referral rate is higher than reported RT utilization rates likely due to denominator used to calculate the final rate. In previously published series, the denominator is usually total number of RPs, whereas we report on a subgroup of patients undergoing RP who have HRF and $\mathrm{PSA}<0.2 \mathrm{ng} / \mathrm{ml}$.

\section{Can we do better? Are there strategies to improve guideline implementation and adherence?}

Prior et al systematically reviewed published literature on effectiveness and implementation of clinical guidelines and reported compliance rates of $0-60 \%{ }^{24}$ They found that strategies that involve passive dissemination were associated with the lowest compliance rates, whereas strategies that included multifaceted interventions, such as auditing, peer review, and feedback, had higher compliance rates. Others have also reported that active strategies, such as educational activities within institutions, supplementary professional information, and patient education improved guideline compliance. ${ }^{25,26}$ Similarly, in the case of prostate cancer, in addition to publishing guidelines and consensus statements in peer-reviewed journals, the above strategies must be adopted to improve the referral of men with HRF for a discussion regarding aRT.

Furthermore, referring physicians must be brought on board. Management that includes aRT meets a medical need for patients and medical system. Showalter et al. constructed a decision analysis model based on the SWOG 8794 patient population and concluded that aRT is not only efficacious, but also cost-effective compared to observation post-RP. ${ }^{27}$ These analyses are helpful not only for guideline formulation and decision-makers, but also provide additional evidence to referring physicians regarding benefit of aRT.

\section{Limitations}

We recognize that this study has limitations inherent to its design as a retrospective analysis. Furthermore, there are many patients for whom the pathological data was not available, especially those who were treated in 2005, a limitation of the data available in the electronic medical records at 
that time. In addition, issues of access to care are important to consider; many patients would have been treated in non-urban, non-tertiary hospitals, thus limiting their access to cancer service delivery. So as to contextualize our data, we do not have the observed population level RT utilization rates to assess changes in trend of RT utilization pre- and post-publication of guidelines.

Nonetheless, this is the first and largest study to report on the population-based referral rates of patients with HRF to RO after RP. We have identified potential areas for improvements in dissemination and implementation of clinical guidelines.

\section{Conclusion}

RCTs and meta-analyses have shown men with HRF may benefit from aRT post-RP. Men undergoing aRT remain free of biochemical progression for a longer period of time and this may translate into improved local control, improved metastasis-free survival, and delay of androgen-deprivation therapies. Despite a modest increase in referral rates to RO post-RP from 2005 2012, more than 50\% of patients sampled with HRF did not receive a RO referral. Initiatives to improve guideline compliance could include urologists and radiation oncologists working in a multidisciplinary care setting, clinician education, and additional strategies to improve interdisciplinary communication.

Competing interests: The authors report no competing personal or financial interests.

This paper has been peer-reviewed.

\section{References}

1. Gray PJ, Lin C, Jemal A, et al. Recent trends in the management of localized prostate cancer: Results from the national cancer data base. Int I Radiat Oncol Biol Phys 2014;90:S431-2.

2. Thompson IM Jr, Tangen CM, Paradelo J, et al. Adjuvant radiotherapy for pathologically advanced prostate cancer: A randomized clinical trial. JAMA 2006;296:2329-35. http://dx.doi.org/10.1001/ jama.296.19.2329

3. Bolla $M$, van Poppel $H$, Collette $L$, et al. Postoperative radiotherapy after radical prostatectomy: A randomized, controlled trial (EORTC trial 22911). Lancet 2005;366:572-8. http://dx.doi. org/10.1016/50140-6736(05)67101-2

4. Wiegel $T$, Bottke D, Steiner U, et al. Phase 3 postoperative adjuvant radiotherapy after radical prostatectomy compared with radical prostatectomy alone in $\mathrm{pT} 3$ prostate cancer with postoperative undetectable prostate-specific antigen: ARO 96-02/AUO AP 09/95. J Clin Oncol 2009;27:2924-30. http://dx.doi. org/10.1200/JC0.2008.18.9563

5. Thompson IM, Tangen CM, Paradelo J, et al. Adjuvant radiotherapy for pathological T3NOMO prostate cancer significantly reduces risk of metastases and improves survival: Long-term followup of a randomized clinical trial. J Urol 2009;181:956-62. htrp://dx.doi.org/10.1016/i.juro.2008.11.032

6. Bolla $M$, van Poppel $H$, Tombal $B$, et al. Postoperative radiotherapy after radical prostatectomy for highrisk prostate cancer: Long-term results of a randomized, controlled trial (EORTC trial 22911). Lancet 2012;380:2018-27. http://dx.doi.org/10.1016/S0140-6736(12)61253-7

7. Morgan SC, Waldron TS, Eapen L, et al. Adjuvant radiotherapy following radical prostatectomy for pathologic T3 or margin-positive prostate cancer: A systematic review and meta-analysis. Radiother Oncol 2008;88:19. http://dx.doi.org/10.1016/i.radonc.2008.04.013
8. Pickles T, Morgan S, Morton G, et al. Adjuvant radiotherapy following radical prostatectomy: Genitourinary Radiation Oncologists of Canada consensus statement. Can Urol Assoc J 2008;2:95-9.

9. Thompson IM, Valicenti RK, Albertsen P, et al. Adjuvant and salvage radiotherapy after prostatectomy: AUA/ASTRO guideline. J Urol 2013;190:441-9. http://dx.doi.org/10.1016/i.juro.2013.05.032

10. Freedland SJ, Rumble RB, Finelli $A$, et al. Adjuvant and salvage radiotherapy after prostatectomy: American Society of Clinical Oncology clinical practice guideline endorsement. J Clin Oncol 2014;32:3892-8. http://dx.doi.org/10.1200/JC0.2014.58.8525

11. Canadian Institue of Health Information, CIHI. Discharge abstract database data quality study: Preliminary year 1 findings. https://secure.cihi.ca/free_products/profile_e_DADDQStudy.pdf. Accessed July 4, 2016.

12. Hagen $B, O^{\prime} B$ eirne $M$, Desai $S$, et al. Innovations in the ethical review of health-related quality improvement and research: The Alberta Research Ethics Community Consensus Initiative (ARECCI). Health Policy. 2007;2:e164-77. http://dx.doi.org/10.12927/hcpol.2007.18865

13. Daly $T$, Hickey BE, Lehman $M$, et al. Adjuvant radiotherapy following radical prostatectomy for prostate cancer. Cochrane Database Syst Rev 2011;(12):CD007234. http://dx.doi.org/10.1002/14651858. cd007234.pub2

14. Delaney $G$, Jacob S, Barton $M$. Estimating the optimal external-beam radiotherapy utilization rate for genitourinary malignancies. Cancer 2005;103:462-73. http://dx.doi.org/10.1002/cncr.20789

15. Kerba $M$, Miao Q, Zhang-Salomons J, et al. Defining the need for prostate cancer radiotherapy in the general population: A criterion-based benchmarking approach. Clin Oncol (R Coll Radiol) 2010;22:801-9. http://dx.doi.org/10.1016/i.lon.2010.07.006

16. Tyldesley S, Delaney G, Foroudi F, et al. Estimating the need for radiotherapy for patients with prostate, breast, and lung cancers: Verification of model estimates of need with radiotherapy utilization data from British Columbia. Int J Radiat Oncol Biol Phys 2011;79:1507-15. http://dx.doi.org/10.1016/i. iirobp.2009.12.070

17. Tyldesley S, Peacock M, Morris JW, et al. The need for, and utilization of prostate-bed radiotherapy after radical prostatectomy for patients with prostate cancer in British Columbia. Can Urol Assoc J 2012;6:89-94. http://dx.doi.org/10.5489/cuaj.11158

18. Zimmermann $M$, Taussky D, Delouya $G$, et al. Radiation therapy after radical prostatectomy: A single-centre radiation oncology experience in trends of referral and treatment practices. Can Urol Assoc J 2015;9:E60812. http://dx.doi.org/10.5489/cuai.2815

19. Sheets NC, Hendrix LH, Allen IM, et al. Trends in the use of postprostatectomy therapies for patients with prostate cancer: A surveillance, epidemiology, and end results medicare analysis. Cancer 2013;119:3295301. http://dx.doi.org/10.1002/cncr.28222

20. Stephenson AJ, Kattan MW, Eastham JA, et al. Prostate cancer-specific mortality after radical prostatectomy for patients treated in the prostate-specific antigen era. J Clin Oncol 2009;27:4300-5. http://dx.doi. org/10.1200/JC0.2008.18.2501

21. Macdonald OK, D'Amico AV, Sadetsky N, et al. Adjuvant radiotherapy in prostate cancer: Predictors of prostate-specific antigen recurrence from the CaPSURE database. Urology 2007;70:106-10. http://dx.doi.org/10.1016/i.urology.2007.03.018

22. Schreiber D, Rineer J, Yu JB, et al. Analysis of pathologic extent of disease for clinically localized prostate cancer after radical prostatectomy and subsequent use of adjuvant radiation in a national cohort. Cancer 2010;116:5757-66. http://dx.doi.org/10.1002/cncr.25561

23. Sineshaw HM, Gray PJ, Efstathiou JA, et al. Dedining use of radiotherapy for adverse features after radical prostatectomy: Results from the national cancer data base. Eur Urol 2015;68:768-74. http://dx.doi. org/10.1016/i.eururo.2015.04.003

24. Prior $M$, Guerin $M$, Grimmer-Somers $K$. The effectiveness of clinical guideline implementation strategies - a synthesis of systematic review findings. J Eval Clin Pract 2008; 14:888-97. http://dx.doi. org/10.1111/i.1365-2753.2008.01014.x

25. Williams DJ, Edwards KM, Self WH, et al. Antibiotic choice for children hospitalized with pneumonia and adherence to national guidelines. Pediatrics 2015;136:44-52. http://dx.doi.org/10.1542/peds.20143047

26. Kulczycki A, Qu H, Shewchuk R. Primary care physicians' adherence to guidelines and their likelihood to prescribe the human papillomavirus vaccine for 11-and 12-year-old girls. Womens Health Issues 2016;26:34-9. http://dx.doi.org/10.1016/i.whi.2015.07.012

27. Showalter TN, Foley KA, Jutkowitz $\mathrm{E}$, et al. Costs of early adjuvant radiation therapy after radical prostatectomy: A decision analysis. Ann Oncol 2012;23:701-6. http://dx.doi.org/10.1093/annonc/mdr281

Correspondence: Dr. Amandeep Taggar, Tom Baker Cancer Centre, Calgary, AB, Canada; astaggar@ucalgary.ca 